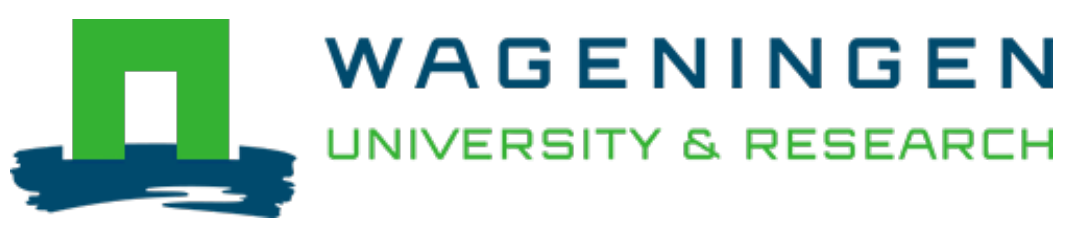

\title{
Consumer attitudes towards hypoallergenic apples that alleviate mild apple allergy
}

Food Quality and Preference

Schenk, M.F.; Maas, M.P.; Smulders, M.J.M.; Gilissen, L.J.W.J.; Fischer, A.R.H. et al

https://doi.org/10.1016/j.foodqual.2010.08.003

This article is made publicly available in the institutional repository of Wageningen University and Research, under the terms of article $25 \mathrm{fa}$ of the Dutch Copyright Act, also known as the Amendment Taverne. This has been done with explicit consent by the author.

Article $25 \mathrm{fa}$ states that the author of a short scientific work funded either wholly or partially by Dutch public funds is entitled to make that work publicly available for no consideration following a reasonable period of time after the work was first published, provided that clear reference is made to the source of the first publication of the work.

This publication is distributed under The Association of Universities in the Netherlands (VSNU) 'Article $25 \mathrm{fa}$

implementation' project. In this project research outputs of researchers employed by Dutch Universities that comply with the legal requirements of Article $25 \mathrm{fa}$ of the Dutch Copyright Act are distributed online and free of cost or other barriers in institutional repositories. Research outputs are distributed six months after their first online publication in the original published version and with proper attribution to the source of the original publication.

You are permitted to download and use the publication for personal purposes. All rights remain with the author(s) and / or copyright owner(s) of this work. Any use of the publication or parts of it other than authorised under article $25 \mathrm{fa}$ of the Dutch Copyright act is prohibited. Wageningen University \& Research and the author(s) of this publication shall not be held responsible or liable for any damages resulting from your (re)use of this publication.

For questions regarding the public availability of this article please contact openscience.library@,wur.nl 


\title{
Consumer attitudes towards hypoallergenic apples that alleviate mild apple allergy
}

\author{
Martijn F. Schenk ${ }^{\mathrm{a}, \mathrm{b}, \mathrm{c}}$, Marinus P. van der Maas ${ }^{\mathrm{d}}$, Marinus J.M. Smulders ${ }^{\mathrm{a}, \mathrm{b}}$, Luud J.W.J. Gilissen ${ }^{\mathrm{a}, \mathrm{b}}$, \\ Arnout R.H. Fischer ${ }^{c}$, Ivo A. van der Lans ${ }^{c}$, Evert Jacobsen ${ }^{\mathrm{e}}$, Lynn J. Frewer ${ }^{\mathrm{c}, *}$ \\ ${ }^{a}$ Wageningen UR, Plant Research International, Droevendaalsesteeg 1, 6708 PB Wageningen, The Netherlands \\ ${ }^{\mathrm{b}}$ Wageningen UR, Allergy Consortium Wageningen, P.O. Box 16, 6700 AA Wageningen, The Netherlands \\ ${ }^{c}$ Wageningen UR, Department of Marketing and Consumer Behaviour, Hollandseweg 1, 6706 KN Wageningen, The Netherlands \\ ${ }^{\mathrm{d}}$ Wageningen UR, Applied Plant Research, P.O. Box 200, 6670 AE Zetten, The Netherlands \\ ${ }^{\mathrm{e}}$ Wageningen UR, Laboratory of Plant Breeding, Droevendaalsesteeg 1, 6708 PB Wageningen, The Netherlands
}

\section{A R T I C L E I N F O}

\section{Article history:}

Received 7 July 2009

Received in revised form 2 July 2010

Accepted 4 August 2010

Available online 10 August 2010

\section{Keywords:}

Risk perception

Benefit perception

Food choice

Food allergy

Genetic modification

Sustainability

Food production

\begin{abstract}
A B S T R A C T
The development of genetically modified (GM) foods with benefits for consumers may be more acceptable than GM foods with benefits that accrue to industry or producers. The Santana apple is a novel hypoallergenic product suitable for many apple allergic consumers with mild symptomology. The Santana also needs fewer pesticides to be applied in production. A survey was conducted among consumers who bought the Santana in a large-scale "sales pilot". The Santana was perceived to be beneficial by many apple allergic consumers. Non-allergic consumers were less positive about genetically modified hypoallergenic apples. Overall, traditional breeding was the preferred production strategy, although acceptance of genetic modification as a process did increase with increasing perceived personal benefit associated with products, in particular those which were "medically-related", or perceived to reduce allergic reactions. Consumer preferences for reduced pesticide usage were also found, although this was more contingent on type of production processes applied.
\end{abstract}

(c) 2010 Elsevier Ltd. All rights reserved.

\section{Introduction}

Prevalence estimates for food allergy range from $1 \%$ to $11 \%$ of the population depending on the allergenic food and characteristics of individuals affected (Rona et al., 2007). Hypoallergenic foods are defined as foods that do not, or are less likely to, provoke allergic reactions compared to their traditional counterparts. As such, they may have a positive impact on the quality of life of food allergic consumers. Genetic modification (GM) may aid in the development of such hypoallergenic foods by application of gene silencing and the consequent elimination of particular allergens. Examples are transgene-induced silencing of allergens in soy, tomato and peanut (Dodo, Konan, Chen, Egnin, \& Viquez, 2008; Gilissen et al., 2005; Herman, Helm, Jung, \& Kinney, 2003; Le et al., 2006).

It is important to understand whether consumers accept both the novel products of GM as well as the production process applied (Frewer et al., 2004; van Kleef, van Trijp, \& Luning, 2005). Some European consumers are concerned about the application of GM to food production in particular (Gaskell et al., 2006). There is evidence to suggest that consumer acceptance of GM is driven by consumer recognition of specific and personally relevant benefits in some cases (Schenk et al., 2008; Yee et al., 2008). Against this, con-

\footnotetext{
* Corresponding author. Tel.: +31 31748 2550; fax: +31 317484361 .

E-mail address: Lynn.Frewer@wur.nl (L.J. Frewer).
}

sumer perceptions that the benefits associated with GM accrue to industry and producers, as opposed to consumers, militates against consumer acceptance (Miles \& Frewer, 2001). Even when applications of GM are developed with concrete and tangible consumer benefits, attitudes towards GM applied to food production are influenced by case-specific characteristics of the application, such as which type of organism is modified and to what purpose (Frewer, Howard, Hedderley, \& Shepherd, 1997; Frewer, Howard, \& Shepherd, 1997; Zechendorf, 1994), as well as the characteristics of specific consumers (Schenk et al., 2008). Consumer acceptance will also vary according to identifiable individual differences in attitudes, such as those towards the environment or concerns about the "unnaturalness" of products (Frewer et al., 1997) or the level of certainty perceived by allergic consumers regarding their safety (Frewer et al., 2004). Development of novel foods where their production is associated with a reduced environmental impact might, for example, constitute a personally relevant benefit to consumers with high levels of environmental concern, which might potentially offset broader concerns about uncontained releases of GM organisms. Development of hypoallergenic foods through the application of GM may also be an example of such a specific and personally relevant benefit that concerns human health, in particular for food allergic consumers.

In light of potential consumer concerns, the availability of alternative strategies, besides GM, to achieve the same benefits should 
also be taken into consideration. To date, dietary exclusion of allergenic foods and ingredients is the only effective strategy to deal with food allergies (Ortolani et al., 1999; Zeiger, 2003). Dietary exclusion is dependent on effective communication regarding allergens to facilitate consumer choice in the retail environment. An example would be effective end-point labelling (CornelisseVermaat, Voordouw, Yiakoumaki, Theodoridis, \& Frewer, 2008; Mills et al., 2004; van Putten et al., 2006). Avoidance of allergenic foods imposes restrictions on social activities and may have a severe impact on the life of sufferers and that of their families (Fernandez-Rivas \& Miles, 2004). Both inaccurate and precautionary ("may contain") labelling might lead to unnecessary restrictions in the diet of allergic individuals and their families (Hourihane, 2001; McCabe, Lyons, Hodgson, Griffiths, \& Jones, 2001), which implies that the development of hypoallergenic alternatives may offer an attractive alternative risk-management strategy. Different strategies can be applied to develop hypoallergenic foods. The allergenicity of food products can be reduced or eliminated by food processing (Brenna et al., 2000; Primavesi et al., 2006). Breeding for varieties with a lower concentration of allergens or which possess protein variants with a reduced allergenicity (Ahrazem et al., 2007; Wangorsch, Ballmer-Weber, Rösch, Holzhauser, \& Vieths, 2007) may also result in hypoallergenic foods. Such processes are, however, time consuming. For example, the average time from crossing a new apple variety to selling it on the market is 20 years.

Apple is a cause of food allergy among consumers in northern European countries. The majority of apple allergic consumers experience relatively mild symptoms that characterize Oral Allergy Syndrome (OAS), which is caused by an IgE-mediated cross-reactivity between pollen allergens and food proteins (Bohle et al., 2005; Fritsch et al., 1998; Lüttkopf et al., 2002; Wiche et al., 2005). GM hypoallergenic apples are being developed in which the Mal d 1 allergen has been silenced (Gilissen et al., 2005). A reduced application of pesticides to fight diseases such as scab and late blight may also be achieved by introduction of disease resistance by GM (Borejsza-Wysocka et al., 2008; Faize et al., 2004). Alternatives are also available as apple varieties vary in the extent to which they cause allergic reactions (Bolhaar et al., 2005; Carnés, Ferrer, \& Fernández-Caldas, 2006) and are able to resist disease (Cheng et al., 1998; Durel et al., 2003).

A traditionally bred apple cultivar, called Santana has been identified as having a reduced allergenicity through application of skin prick tests (Bolhaar et al., 2005). Reduction of allergy can be induced by all three methods (traditional breeding, cisgenic methods transgenic methods). However, the number of allergic consumers that would benefit by having a reduced allergic reaction, the time it would take to produce a variety, and the consumer acceptance of the product will vary between the three methods. Therefore, all three were included in the conjoint study.

Selective breeding may further enhance the hypoallergenic characteristics in progeny of the Santana apple, but this process may take up to 20 years. Approaches that utilize cisgenes may speed up this process, while gene silencing by GM may result in complete absence of particular allergens and is therefore likely to result in apples that are hypoallergenic for a larger group of allergic consumers. Furthermore, it is hypothesized that cisgenic and transgenic approaches may differ in consumer acceptance.

The Santana apple has been identified as having a reduced allergenicity through application of skin prick tests (Bolhaar et al., 2005). Kootstra, Vlieg-Boerstra, and Dubois (2007) estimated that the Santana apple would produce a reduced allergic reaction in over $50 \%$ of the apple allergic consumers and is considered suitable for consumption by consumers with mild apple allergy based on a food challenge study. Selective breeding may further enhance the hypoallergenic characteristics in progeny of the Santana apple. However, the GM approach is likely to result in apples that are hypoallergenic for a larger group of allergic consumers, because it may result in complete absence of particular allergens by means of gene silencing. The availability of Santana has, so far, been very limited in volume. In addition to increased hypoallergenicity, the Santana is resistant against scab and therefore requires less spraying of pesticides, which makes it an attractive apple for organic production.

The present study focuses on consumer perceptions of risks and benefits of genetically modified foods using "hypothetical apple profiles". In these profiles, GM or traditional breeding had been used to introduce two consumer benefits. The impact of both a personal health benefit (hypoallergenicity) and an environmental benefit (fewer pesticides required in production) were examined. Data on the apple profiles were combined with data on consumer reactions to a currently available hypoallergenic apple (the Santana) to determine whether "real-life" experience with a hypoallergenic product influenced consumer attitudes towards hypoallergenic products in general. The Santana was expected to induce no, or reduced, allergic reaction in the majority of consumers with self-reported apple allergy.

\section{Methods}

\subsection{Data collection}

The survey was carried out between September 2006 and June 2007. From September 2006 to April 2007, the Santana apple was sold by one large supermarket chain, in several organic food stores and at several greengrocers in the Netherlands. In the supermarket, the apple was packaged with an explanatory leaflet which contained information about the hypoallergenic properties of the Santana and apple allergy. The leaflet provided information on apple allergy and a consumption protocol for apple allergic consumers. A request was also made to consumers to participate in an internet-based survey about the Santana. The majority of consumers who responded to this request self-reported suffering from apple allergy. In order to create a control group of non-apple allergic consumers, further participants were recruited by convenience sampling from an existing panel. The survey took about 8 minutes to complete, and respondents could participate in a lottery for a gift voucher of 50 euro.

\subsection{Survey design}

An internet survey was designed, which included a conjoint study (Hair, Black, Babin, \& Andserson, in press) in which respondents were asked to rate hypothetical apples with different levels of three attributes that were varied in the apple's description (Table 1). The hypothetical examples included in the conjoint study reflected novel apples with a combination of different attributes which currently exist, are currently under development, or can potentially be developed in the future. The combinations of alternative levels from the three attributes are termed "apple profiles" throughout the remainder of this paper. Pesticide and allergy reduction levels were determined in collaboration with plant breeding experts in order to reflect realistically attainable reduction levels. A 5\% reduction in pesticide use was used in the descriptions instead of $0 \%$ to maintain the validity of the apple descriptors. With respect to breeding method, a distinction was made between GM utilizing material from other plant species and from other apple varieties. This reflects recent developments associated with "cisgenes", (genes from the crop plants themselves or from crossable species) (Jacobsen \& Schouten, 2007). The apple profile descriptions were tested for comprehension and understanding in a pilot survey that was conducted in 2006 (descriptions avail- 
Table 1

Conjoint study of apples: attributes and levels.

\begin{tabular}{ll}
\hline Attribute & Level description \\
\hline $\begin{array}{c}\text { Breeding } \\
\text { method }\end{array}$ & - Traditional breeding \\
& - Genetic modification using material from other plant \\
& species \\
& - Genetic modification using material from other apple \\
& varieties \\
Pesticide usage & $-5 \%$ pesticide reduction during growing \\
& $-50 \%$ pesticide reduction during growing \\
Apple allergy & $-5 \%$ of apple allergic consumers without complaints \\
& $-66 \%$ of apple allergic consumers without complaints \\
& $-95 \%$ of apple allergic consumers without complaints
\end{tabular}

able from the authors on request ${ }^{1}$ ). The pilot survey was completed by a convenience sample of 15 Dutch respondents. No adaptations were made on the basis of the pilot results.

Respondents initially evaluated a "warm-up" apple profile. Respondents then rated nine profiles on two items. The first item measured to what extent respondents liked the apple under consideration, using a seven-point scale from "1. do not like at all" to "7. like very much". The second item measured their willingness to buy the apple by asking them to rate their agreement with the statement "if this apple was sold in the supermarket, I would buy this apple" on a seven-point scale from "1. completely disagree" to "7. completely agree".

A full-factorial within subject-design would require each respondent to evaluate a set of $(3 \times 2 \times 3=) 18$ apple profiles. Previous research has indicated that respondents have difficulties in rating such a large number of profiles (Jan, Fu, \& Huang, 2007). Therefore, a fractional-factorial design was applied in order to reduce the number of profiles presented to each respondent. The design was created with the conjoint module in SPSS 15.0. Nine apple profiles were created and attributed to three clusters (1-3) of three profiles each by using a blocking factor. Respondents were randomly assigned to groups A-C. Each group evaluated two clusters of profiles in a balanced incomplete block design $(A: 1+2$; $B: 1+3$; $C: 2+3)$. No significant differences were observed for demographic and allergy characteristics between the three groups. Each profile was described on a separate page.

The remainder of the survey included items that were derived from previous research on acceptance of GM (Frewer et al., 1997; Schenk et al., 2008) to allow an interpretation of individual differences in acceptance or rejection of hypoallergenic GM apples in terms of attitudinal variables. The scales were adapted from the original items applied in Schenk et al. (2008). The face validity of the items is reasonable. Two items measured the self-reported overall health of the respondents (item health 1 and 2, Cronbach $\alpha=0.66$; Schenk et al., 2008). Two items measured the general attitude towards application of GM in food (item GM attitude 1 and 11; Cronbach $\alpha=0.72$; Schenk et al., 2008). One item measured the environmental concern (item environment 3; Schenk et al., 2008) and one item consumers' preference for organic, as opposed to conventionally grown products. Responses to the health and attitude items were collected on anchored seven-point scales.

In addition, the survey included items about the purchase location of the Santana apple, the self-reported occurrence of an allergic response following consumption of the Santana apple, and the consumer's use of allergy medication following consumption. Respondents were asked to rate the Santana on a seven-point scale anchored by " 1 . do not like at all" to "7. like very much". Information was collected about the self-reported occurrence of allergic disorders, allergy diagnosis, and substances to which allergic

\footnotetext{
1 Martijn.Schenk@wur.nl
}

respondents reacted (apple, other fruits, other foods, pollen and other substances). Respondents with an apple allergy were asked to report the severity of their allergic reaction to apples in general. Finally, selected demographic characteristics were recorded (age, gender, and education level).

\subsection{Statistical analysis}

All statistical procedures were performed in SPSS 15.0. The ratings on the apple profiles were subjected to a repeated measures mixed linear model. This procedure can be applied to analyze conjoint data from an incomplete block design (Maas \& Snijders, 2003). Models were fitted using the residual maximum likelihood (REML) algorithm. Initially, a step down test was performed (significance level at $p=0.05$ ) using the deviance values for the covariance matrix to arrive at a well-fitting covariance structure (Maas \& Snijders, 2003). The "unstructured" covariance matrix fitted significantly better $($ CAIC $=8555,847$; number of parameters $=45)$ than the first more simplified model (CAIC $=8653,652$; number of parameters $=18$ ) and was therefore retained for the analysis.

The analysis of the conjoint attributes was limited to main effects due to the study design. As demographic variables are known to influence attitude towards GM (Siegrist, 1998; Titchener \& Sapp, 2002), age and gender were introduced as covariates in the multilevel analysis to correct for this. To explain individual differences, distinctions were made between: (1) respondents who were allergic to apple and those who were not, (2) respondents with a high or low preference for organic foods (application of a median-split to the item that measured preference for organic food products), and (3) respondents who perceived a high or low risk associated with GM by applying a median-split to the item that measured perceived risk of GM in food. Two-way interactions between conjoint attributes and these three explanatory variables were included in the model.

\section{Results}

\subsection{Demographic and allergy characteristics}

In total, 437 respondents were recruited. Forty respondents with multiple missing data in the apple-profile ratings, attitude measurements or in the demographic characteristics were excluded, leaving 397 respondents contributing data to the analysis, 300 of whom had eaten the Santana apple. The demographic characteristics of the respondents revealed that women and people with a high education level (B.Sc. or M.Sc.) were overrepresented in the sample (Table 2). This sampling effect is likely to be due to self-selection bias. Women are more involved with food shopping (Lake et al., 2006), while highly educated people are more likely to respond to internet-based surveys (Cook, Heath, \& Thompson, 2000).

The respondents were characterized according to their self-reported allergy complaints (Table 2). The majority of the respondents reported allergies, which was expected as most respondents were recruited through the leaflet from the Santana package, and people who are food allergic may also be more motivated to respond. Many of the allergic respondents reported that their allergy was diagnosed by a general practitioner (30\%) or an allergologist (45\%) (Table 2), although it is necessary to interpret all the allergy diagnoses as self-reported.

\subsection{Consumer attitude towards apple profiles}

The items that measured respondents' "liking" and "willingness to buy" of the apple profiles in the conjoint study were highly correlated $(r=0.92, p<0.001)$ and were averaged to calculate a 
Table 2

Demographic characteristics from participating respondents and their self-reported allergy background $(N=397)$.

\begin{tabular}{lll}
\hline Characteristic & & $\begin{array}{l}\text { Number of } \\
\text { respondents (\%) }\end{array}$ \\
\hline Gender & Male & $134(34)$ \\
& Female & $263(66)$ \\
Age (mean $\pm S D)$ & & $39 \pm 12.6$ \\
Allergy diagnosis & No allergy & $63(16)$ \\
& Allergy, self-diagnosed & $83(21)$ \\
& Allergy, diagnosed by GP & $101(25)$ \\
& Allergy, diagnosed by & $150(38)$ \\
Allergic complaints & allergologist & \\
$(n=334)$ & Apple allergy (and other & $238(71)$ \\
& fruits) & $60(18)$ \\
& Apple allergy (no other & \\
fruits) & $36(11)$ \\
$(n=294)$ & Other allergy & $82(28)$ \\
& Mild & $181(61)$ \\
& Considerable & $31(10)$ \\
& Severe & $0(0)$ \\
& Very severe & $4(1)$ \\
\hline
\end{tabular}

Table 3

Repeated measure mixed linear model explaining the attitude towards the apple profiles.

\begin{tabular}{lcrc}
\hline Fixed effects & $\left(\mathrm{df}_{\text {effect }}, \mathrm{df}_{\text {error }}\right)$ & $F$ value & $p$ value \\
\hline Main effects & & & \\
Breeding method & $(2,364)$ & 96.253 & $<0.001$ \\
Pesticide reduction & $(1,372)$ & 139.517 & $<0.001$ \\
Allergy reduction & $(2,367)$ & 206.746 & $<0.001$ \\
Apple allergy & $(1382)$ & 0.113 & 0.74 \\
Organic products & $(1381)$ & 1.870 & 0.17 \\
GM Risk & $(1381)$ & 8.256 & $<0.01$ \\
Gender & $(1380)$ & 3.282 & 0.07 \\
Age & $(1379)$ & 5.306 & $<0.05$ \\
Interaction effects & & & \\
Breeding method $\times$ GM risk & $(2,358)$ & 36.582 & $<0.001$ \\
Breeding method $\times$ organic products & $(2,359)$ & 0.982 & 0.38 \\
Breeding method $\times$ apple allergy & $(2,364)$ & 13.233 & $<0.001$ \\
Pesticide reduction $\times$ GM risk & $(1,369)$ & 0.010 & 0.76 \\
Pesticide reduction $\times$ organic products & $(1,370)$ & 15.065 & $<0.001$ \\
Pesticide reduction $\times$ apple allergy & $(1,373)$ & 7.848 & $<0.01$ \\
Allergy reduction $\times$ GM risk & $(2,368)$ & 9.571 & $<0.001$ \\
Allergy reduction $\times$ organic products & $(2,369)$ & 1.856 & 0.16 \\
Allergy reduction $\times$ apple allergy & $(2,368)$ & 65.832 & $<0.001$ \\
\hline
\end{tabular}

single scale, which was labeled "attitude". In this study, "liking" was interpreted as represented another indicator of "purchase intention", in particular because the two measures were highly correlated. The combined measure was therefore labeled "attitude" (towards the GM apple).
Table 3 gives the results that were obtained through application of the repeated measures mixed linear model on these scores. The main effects of "breeding method", "pesticide reduction" and "allergy reduction" were tested and their interaction with "perceived GM risk", "apple allergy" and "preference for organic products" was assessed. All other health and attitudinal items included in the survey had no effect on attitude when these items were included, and were therefore omitted from further analysis.

\subsection{Breeding method}

The results indicate that the breeding method utilized has a significant effect on consumer attitude (Table 3). Attitudes towards apple profiles differed significantly between the different breeding methods used (Table 4). Traditional breeding was rated more positively than both GM strategies. GM with genes from another apple (cisgenes) was rated more positively than GM with genes from another plant species. The difference between the two GM strategies was significant, but the effect size was approximately six times smaller when compared to the difference between the GM methods and conventional breeding. Hence, it is questionable whether the difference between the two GM methods is relevant as far as consumer acceptance is concerned. Significant interaction effects between breeding methods and both "perceived GM risk" and "apple allergy" were found. Respondents who consider GM to be low in risk differentiated between traditional breeding and the GM strategies, but the differences were much less pronounced than for respondents who consider GM to be high in risk (Fig. 1). Differences in preferences between the breeding strategies were less pronounced among apple allergic respondents than among respondents without an apple allergy.

\subsection{Pesticide reduction}

The apple profiles with greater benefits (higher levels of pesticide reduction and greater hypoallergenicity) resulted in more positive attitudes (Table 4). In general, people were positive about pesticide reduction and hypoallergenicity. However, the analysis includes both traditional breeding and GM strategies. Therefore, the analysis focused on whether the properties of the apple profiles are also perceived to be beneficial when only a GM method is involved in their development, or whether the effects reported in Table 3 should be fully attributed to traditionally bred apples. The repeated measures mixed linear model analysis was repeated using the apple profiles that included one of the two GM strategies only (Table 5). Care should be taken when interpreting the results as omitting one level of breeding method may result in the main effects of Hypoallergenicity and Pesticide reduction being confounded.

The results indicate that a reduction of pesticide use during apple production has a significant effect on consumer attitude (Tables 3-5). The respondents were significantly more positive towards a

Table 4

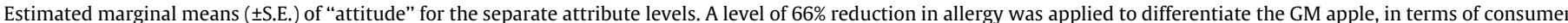
benefit, from the allergy reduction which is feasible through natural breeding, which is $50 \%$.

\begin{tabular}{|c|c|c|c|}
\hline Attribute & Number of levels & Estimated marginal mean. & S.E. \\
\hline \multirow[t]{3}{*}{ Breeding method } & Traditional breeding & 4.75 & 0.071 \\
\hline & Genetic modification using material from other apple varieties & 3.86 & 0.076 \\
\hline & Genetic modification using material from other plant species & 3.64 & 0.075 \\
\hline \multirow[t]{2}{*}{ Pesticide usage } & $5 \%$ pesticide reduction during growing & 3.75 & 0.062 \\
\hline & $50 \%$ pesticide reduction during growing & 4.42 & 0.071 \\
\hline \multirow[t]{3}{*}{ Apple allergy } & $5 \%$ of apple allergic consumers without complaints & 2.98 & 0.079 \\
\hline & $66 \%$ of apple allergic consumers without complaints & 4.25 & 0.077 \\
\hline & $95 \%$ of apple allergic consumers without complaints & 5.02 & 0.078 \\
\hline
\end{tabular}




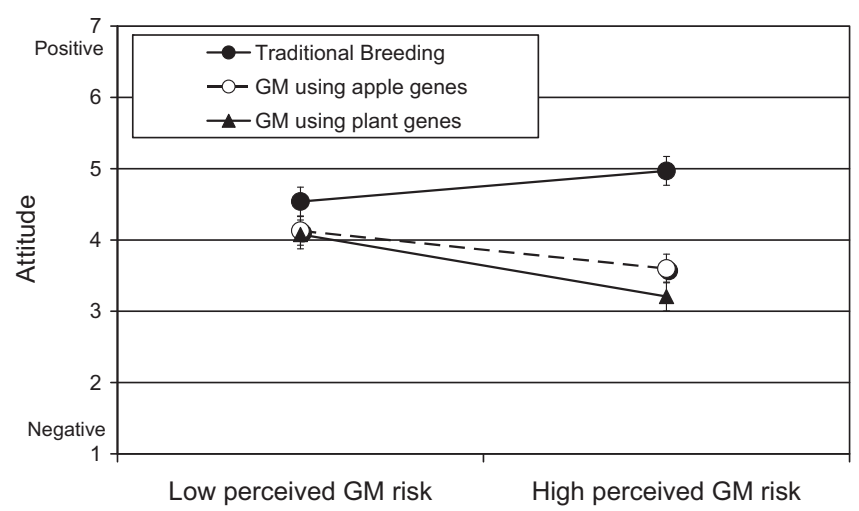

Fig. 1. Interaction effect between applied breeding method and perceived risk of food products. Respondents were separated into groups perceiving high and a low risk by applying a median-split to the item measuring perceived risk of GM in food.

Table 5

Repeated measures mixed linear model explaining the attitude towards the apple profiles that include the application of GM.

\begin{tabular}{lcrc}
\hline Fixed effects & $\left(\mathrm{df}_{\text {effect }}, \mathrm{df}_{\text {error }}\right)$ & $F$ value & $p$ value \\
\hline Main effects & & & \\
Pesticide reduction & $(1,372)$ & 139.517 & $<0.001$ \\
Allergy reduction & $(2,367)$ & 206.746 & $<0.001$ \\
Apple allergy & $(1382)$ & 0.113 & 0.74 \\
Organic products & $(1381)$ & 1.870 & 0.17 \\
GM Risk & $(1381)$ & 8.256 & $<0.01$ \\
Gender & $(1380)$ & 3.282 & 0.07 \\
Age & $(1379)$ & 5.306 & $<0.05$ \\
Interaction effects & & & \\
Pesticide reduction $\times$ GM Risk & $(1,369)$ & 0.010 & 0.76 \\
Pesticide reduction $\times$ organic products & $(1,370)$ & 15.065 & $<0.001$ \\
Pesticide reduction $\times$ apple allergy & $(1,373)$ & 7.848 & $<0.01$ \\
Allergy reduction $\times$ GM Risk & $(2,368)$ & 9.571 & $<0.001$ \\
Allergy reduction $\times$ organic products & $(2,369)$ & 1.856 & 0.16 \\
Allergy reduction $\times$ apple allergy & $(2,368)$ & 65.832 & $<0.001$ \\
\hline
\end{tabular}

$50 \%$ pesticide reduction compared to a $5 \%$ pesticide reduction (Table 4). Significant interaction effects were detected for "organic products" and "apple allergy" (Table 5). Respondents who expressed a high preference for organic products were more negative about the $5 \%$ pesticide reduction than respondents with a low preference for organic products (Fig. 2). The $50 \%$ pesticide reduction was rated equally by all respondents independent of their preferences for organic production. Apple cultivars that resulted in a $5 \%$ pesticide reduction were rated equally by consumers with, and without apple allergy. Respondents tended to be more positive towards a $50 \%$ pesticide reduction, compared to a $5 \%$ reduction, but this was predominantly the case for non-allergic respondents. Allergic respondents showed a smaller effect but still preferred a $50 \%$ reduction over a $5 \%$ pesticide reduction.

\subsection{Allergy reduction}

The results indicate that a perceived reduced occurrence of allergic reactions after apple consumption had a significant effect on consumer attitude (Tables 3-5). The 5\% reduction in the number of allergic responses following consumption was rated significantly less favorably compared to the $66 \%$ reduction, which was in turn rated significantly less favorably than the 95\% reduction (Table 4). Significant interaction effects were found between "allergy reduction" and "apple allergy" and between "allergy reduction" and "perceived GM risk" (Tables 3 and 5). The 66\% allergy reduction was rated similarly by apple allergic respondents and respondents without an apple allergy (Fig. 3). Non-allergic respondents

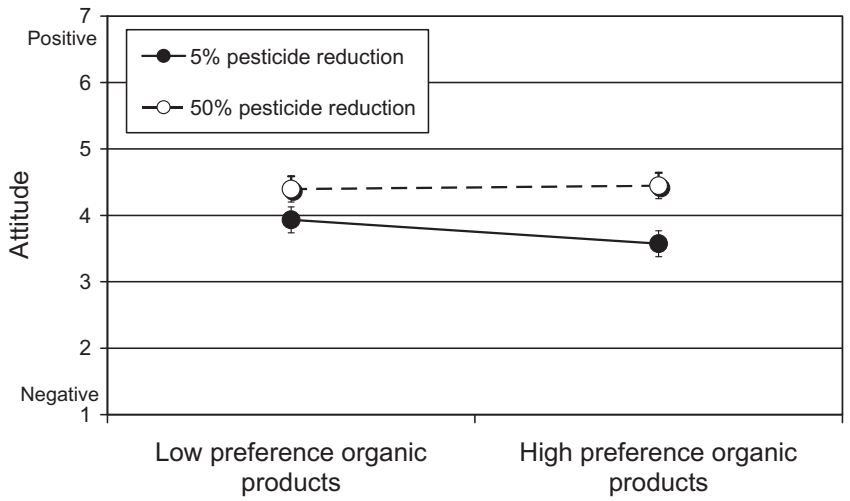

Fig. 2. Interaction effect between pesticide reduction and preference for organic products. Respondents were separated into groups perceiving high and low preference by applying a median-split to the item measuring preference for organic products.

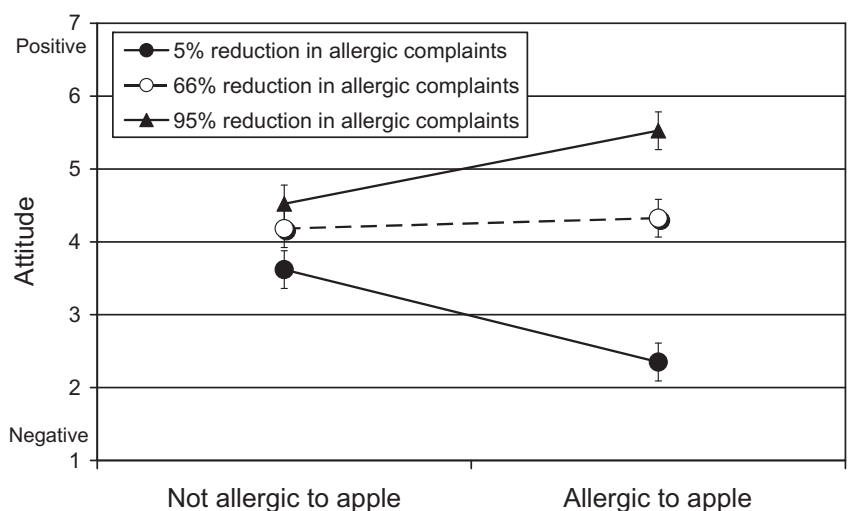

Fig. 3. Interaction effect between allergy reduction of the apple profiles and presence/absence of an apple allergy among respondents. Sixty-six\% allergy reduction was rated similarly by apple allergic respondents and respondents without an apple allergy.

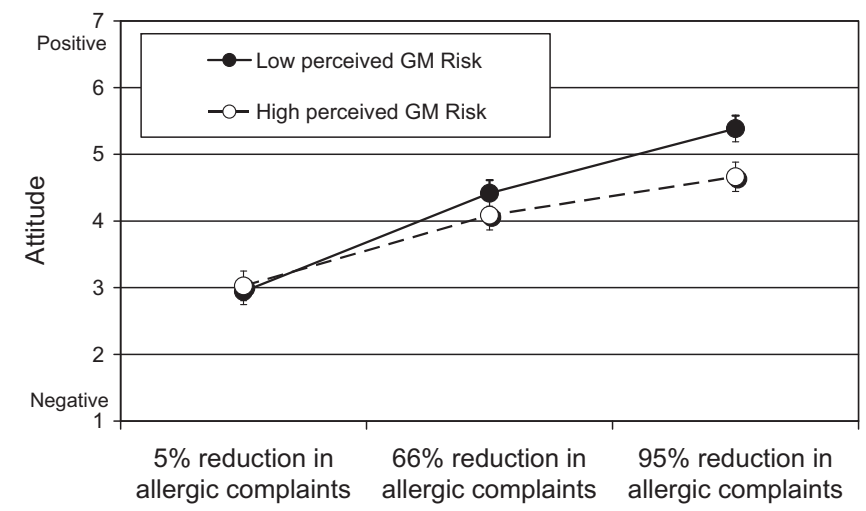

Fig. 4. Interaction effect between allergy reduction of the apple profiles and perceived risk of genetically modified food products.

did not really differentiate between the various levels of allergy reduction, while allergic respondents were relatively more negative about the $5 \%$ reduction. In turn, they were relatively more positive about the $95 \%$ reduction compared to respondents without an apple allergy. Respondents who consider the application of GM to be high in risk were relatively less positive about the $66 \%$ and $95 \%$ reduction than those who consider GM to be low in risk (Fig. 4). 


\subsection{Evaluation of the Santana apple}

To evaluate the sales pilot of the hypoallergenic Santana, the experiences and purchase details of all respondents that had eaten the Santana were summarized (Table 6). Forty-two percent of the apple allergic consumers had no allergic complaints after eating the Santana. The majority of consumers who experienced an allergic reaction after eating the Santana reported the symptoms as being minor. Only $4 \%$ of the respondents reported having serious complaints, while 3\% took allergy medication after eating the Santana. No increase in the occurrence of allergic reactions to the Santana was observed in relation to the number of months after harvesting in which the Santana was consumed (logistic regression; $\beta=-0.018, p=0.82$ ), even though prolonged storage is known to induce an increase in the allergenicity of apples (Bolhaar et al., 2005).

To what extent allergic consumers were positive about the Santana depended on whether they experienced an allergic reaction following consumption, and if so, on the severity of the reaction (Table 7). Many consumers who experienced an allergic reaction indicated that their complaints were less severe compared to complaints experienced following consumption of other apple varieties. This is in concordance with the ratings for liking the Santana; allergy sufferers who reported minor allergic symptoms following consumption of the Santana gave a much higher rating than allergy sufferers who experienced more serious complaints. The difference in liking between allergy sufferers with no allergic reaction and those with very minor ones was relatively small (Table 7).

The Santana has been found to be suitable for consumption by consumers with a mild apple allergy in previous research (Kootstra et al., 2007), as was clearly stated in the explanatory leaflet. The self-reported severity of the respondents' apple allergy was associated with the occurrence of an allergic reaction to the Santana $\left(\chi^{2}=7.35, d f 2, p<0.05\right)$. The majority of the respondents in the current study self-reported that they suffered from mild to consid-

\section{Table 6}

Purchase details and allergic response to the Santana $(N=300)$. Note that Santana is grown both with and without application of organic standards, as it is traditionally bred.

\begin{tabular}{lll}
\hline Characteristic & & $\begin{array}{l}\text { Number of respondents } \\
(\%)\end{array}$ \\
\hline Santana purchased at: & $\begin{array}{l}\text { Supermarket chain } \\
\text { Organic food store }\end{array}$ & $\begin{array}{l}192(64) \\
23(8)\end{array}$ \\
& Greengrocer & $6(2)$ \\
& Elsewhere & $15(5)$ \\
& Not reported & $64(21)$ \\
& Organically grown & $171(57)$ \\
Type Santana purchased & Traditionally & $50(17)$ \\
& grown & $79(26)$ \\
& Don't remember & $119(42)$ \\
Apple allergic consumer that & No complaints & $155(54)$ \\
Experienced allergic & Yes, minor & $12(4)$ \\
complaints & complaints & \\
After eating the Santana & Yes, heavy & \\
$(n=286)$ & complaints &
\end{tabular}

Table 7

Appreciation of the Santana (mean \pm S.D.) as measured on a 1-7 scale $(N=300)$.

\begin{tabular}{lll}
\hline Consumer group & Appreciation & S.D. \\
\hline Apple allergy, no reaction to Santana $(n=119)$ & 6.24 & 0.60 \\
No apple allergy $(n=14)$ & 5.79 & 1.22 \\
Apple allergy, minor reaction to Santana $(n=155)$ & 4.89 & 1.48 \\
Apple allergy, heavy reaction to Santana $(n=12)$ & 1.42 & 0.79 \\
\hline
\end{tabular}

erable allergic reactions to apple. Forty-seven percent of the respondents with a mild apple allergy experienced an allergic reaction to the Santana. In the group with "considerable" allergic reactions to apple this increased to $65 \%$. Ten percent of the respondents reported to suffer from a severe apple allergy, but still tried eating the Santana. Consumers with a severe apple allergy were not advised to try the Santana, but among the respondents in this consumer group who did try the Santana 38\% reported having no allergic reaction. Two other variables were also associated with the occurrence of an allergic reaction following consumption of the Santana, namely the occurrence of other fruit allergies $\left(\chi^{2}=6.77, d f 1, p<0.01\right)$ and age group $\left(\chi^{2}=11.79, d f 5\right.$, $p<0.05)$. The occurrence of an allergic reaction to the Santana increased with an increasing self-reported severity of the apple allergy and with the occurrence of other fruit allergies. The occurrence of an allergic reaction to the Santana decreased with increasing age. Combining these three factors yields the best indication for the occurrence of an allergic reaction.

\subsection{Effect of a negative reaction to Santana on attitude}

For apple allergic consumers who had an allergic reaction to the Santana apple, their first experience with a hypoallergenic food was negative. This may influence their attitude towards similar products, because the benefits claimed for the hypoallergenic product have not proven to be real benefits for these consumers. Therefore, the analysis on the apple profiles was carried out for self-reported apple allergic consumers alone, comparing respondents with or without an allergic reaction to the Santana. The attitude scores for the apple profiles were subjected to a repeated measure mixed linear model, while testing the main effects of "breeding method", "pesticide reduction" and "allergy reduction", and the interaction with "perceived GM risk", "allergic reaction to Santana" and "preference for organic products". No significant interactions between "allergic reaction to Santana" and the three attributes were observed. The other effects were highly similar to the results reported previously; both with respect to significances and effect sizes (see Tables 4 and 5).

\section{Discussion}

This study examined consumer attitudes towards genetically modified foods in which a consumer benefit had been introduced. Both a personally relevant health benefit (hypoallergenicity) and an environmental benefit (fewer pesticides required in production) were examined. The introduction of hypoallergenic properties into food products may have consequences for both food allergy and environmental management, assuming consumer acceptance of the products is achieved.

\subsection{Acceptance of GM food products}

The availability of apples with some degree of hypoallergenicity represents a first step in creating hypoallergenic products. Further breeding may enhance hypoallergenic properties, but this will take time, as the average time from crossing a new variety to selling it in the market is 20 years. To speed up this process, development of hypoallergenic foods may include application of GM (Dodo et al., 2008; Gilissen et al., 2005; Herman et al., 2003; Le et al., 2006). Hypoallergenic GM foods are of interest because they are on the "boundary" between medical- and food-related GM applications. The results of this study suggest consumer preference for traditional breeding over breeding by GM in the development of hypoallergenic apples (Fig. 1), consistent with previous research (Miles et al., 2005; Schenk et al., 2008). Nevertheless, acceptance of 
hypoallergenic GM apples is higher among apple allergic consumers, which is in line with acceptance of medical applications. Caution in generalising this result is required. Symptoms of apple allergy are generally not severe, particularly when compared to other food allergies (for example, anaphylaxis which can be provoked by peanut ingestion in sensitized consumers). Thus, given that a potentially life-threatening situation is highly unlikely to occur when Santana does provoke an allergic reaction, the results cannot be extrapolated to a situation where an allergic reaction to a "hypoallergenic" product might result in fatality.

In the research presented here, it was hypothesized that acceptance of GM products is driven by consumer recognition of specific and personally relevant benefits. The results indicate that "personal benefits" have an impact on GM acceptance (Figs. 2 and 3 ). The effect of an increased allergy reduction on acceptance of GM is stronger for apple allergic consumers, who experience a direct "personal benefit" associated with hypoallergenic GM apples, compared to consumers without apple allergy. In contrast, non-allergic consumers may consider hypoallergenic GM products to be beneficial because these products alleviate complaints of other consumers. A similar argument can be made for GM apples which require less pesticide during their production. Using less pesticide has an effect on acceptance of GM among consumers with a preference for organic products. These people judge environmental effects as more important; hence, the effects of reduced pesticide usage are expected to have a larger impact on their personal preference. However, in the case of consumers who prefer organic products, GM applications are always less acceptable, even if they are associated with reduced pesticide usage because these consumers associate GM with negative impact on environment (Deliza, Rosenthal, Hedderley, MacFie, \& Frewer, 1999). Given that societal attitudes towards GM are influenced by case-specific characteristics of the application, such as which organism is modified and to what purpose (Frewer et al., 1997; Zechendorf, 1994), the area of application may be of relevance here. The majority of the European consumers are positive about many medical applications of GM, whilst at the same time rejecting some agricultural applications. Medical applications are considered more necessary, because of the treatment of illness, and are thereby more acceptable than food-related applications that appeared to benefit the producer, at least for the first generation of GM products (Frewer et al., 1997; Zechendorf, 1994). There is evidence to suggest that consumers tend to have a higher preference for traditionally produced foods if health benefits are equivalent, at least under circumstances when behaviours are not directly measured (Cox, Evans, \& Lease, 2008). In this study, it has been demonstrated that such preferences for traditional approached may not be reflected in actual consumer behaviours, if the benefits resulting from the novel production process are associated with concrete benefits for specific consumers.

\subsection{The hypoallergenic Santana apple}

Around $40 \%$ of the apple allergic consumers reported being able to eat the Santana without experiencing an allergic reaction. It should, however, be kept in mind that the respondents in our study were self-reporting their reactions and were not drawn randomly from the apple allergic population. Although some of these consumers stated that their reaction was less severe than reactions experienced following consumption of other apple varieties, the number of consumers reacting to the Santana was higher than expected. A correlation was observed between the occurrence of an allergic reaction to the Santana and an increasing severity of apple allergy in the self-report data. In addition, the occurrence of an allergic reaction to the Santana increased if respondents were younger. Generally, the severity of allergies decreases with increasing age in adulthood (Barbee, Brown, Kaltenborn, \& Halonen, 1981).

\subsection{Food risk management}

The introduction of hypoallergenic foods may complicate risk management. For example, having to separate allergenic foods and hypoallergenic counterparts requires an increased vigilance from allergic consumers (Gowland, 2001). Furthermore, individual consumers may vary with regard to threshold levels and may have different clinical response profiles because they react to different allergens in the same food. As a result, some food allergy sufferers may still experience an allergic reaction following consumption of hypoallergenic products. In the case of severe reactions, such as anaphylaxis, it is clearly unacceptable to market unlabelled hypoallergenic products.

Two issues require further attention from the perspective of food allergy management. Despite the strong recommendation on the explanatory leaflet that the Santana is only suitable for consumers with a mild apple allergy, this did not stop allergic consumers with severe apple allergy from trying the Santana. In the Dutch context, allergic consumers with a very severe allergic reaction (anaphylactic shock) are unlikely to be found. However, given the potential impact of a severe reaction (severe swelling of the oral mucosa), consumption by such consumers is undesirable, and safe consumption relies heavily on the accurate use of the testing protocol that was described on the explanatory leaflet. The step-bystep testing protocol aims to minimize the consequences of the occurrence of an allergic reaction. How seriously consumers take the protocol, and whether or not they test their reactions to the Santana according to the guidelines provided, is not known. The experience with the Santana may indicate that some allergic consumers will test hypoallergenic food, regardless of whether it is suitable for them. This implies that more explicit warnings are required to prevent consumers with a severe allergy from trying these products, assuming they are deemed safe enough to be commercialized in the first place. Given the outcomes of the current study, a cautious approach is recommended regarding interventions based on hypoallergenic foods, or the use of hypoallergenic products as ingredients, certainly for food products that may cause very severe allergic reactions.

Some limitations to the research need to be mentioned. There is some evidence that attitudes to technology may, in some cases, be related to educational status. This was not statistically analysed in the current paper as the participants were biased towards being more highly educated. This represents a limitation of the current study which merits further investigation in future research. Similarly, cost is potentially a major determinant of acceptance but systematic variation of pricing was not included in the experimental design. For example, if the GM apple had been cheaper the results might have been quite different. This also merits further investigation. Finally, Consumers were not specifically informed about the time it takes for a traditionally bred apple cultivar to reach the market nor about the fact that GM may speed up this process. Preferences might shift towards higher acceptance when this information is included in the experimental design.

\section{Conclusion}

Hypoallergenic foods have the potential to contribute to food allergy management. The results of this study suggest that the Santana may alleviate allergic complaints in nearly half of the (self-reported) apple allergic consumers. Attitudes towards similar 
hypoallergenic products tended to be positive, in particular if consumers perceived that they personally might benefit from the hypoallergenic properties of the new product. The effect was less pronounced for the environmental benefit (reduced pesticide use in production), perhaps because the respondents who were more concerned about the negative environmental impact of pesticides were also more concerned about the environmental impact of genetically modified crops. Traditional breeding methods were still preferred over other production methods, independent of the potential benefits obtained - rather the results suggest that GM was perceived to be more acceptable if participants perceived a personal benefit to be associated with the food.

\section{Acknowledgement}

This research was funded by the Allergy Consortium Wageningen, The Netherlands.

\section{References}

Ahrazem, O., Jimeno, L., López-Torrejón, G., Herrero, M., Espada, J. L., SánchezMonge, R., et al. (2007). Assessing allergen levels in peach and nectarine cultivars. Annals of Allergy, Asthma and Immunology, 99, 42-47.

Barbee, R. A., Brown, W. G., Kaltenborn, W., \& Halonen, M. (1981). Allergen skin-test reactivity in a community population sample: Correlation with age, histamine skin reactions, and total serum immunoglobulin E. Journal of Allergy and Clinical Immunology, 68, 15-19.

Bohle, B., Radakovics, A., Luttkopf, D., Jahn-Schmid, B., Vieths, S., \& Ebner, C. (2005). Characterization of the $\mathrm{T}$ cell response to the major hazelnut allergen, Cor a 1.04: evidence for a relevant $\mathrm{T}$ cell epitope not cross-reactive with homologous pollen allergens. Clinical and Experimental Allergy, 35, 1392-1399.

Bolhaar, S. T. H. P., Van de Weg, W. E., Van Ree, R., Gonzalez-Macebo, E., Zuidmeer, L., Bruijnzeel-Koomen, C. A. F. M., et al. (2005). In vivo assessment with prickto-prick testing and double-blind, placebo-controlled food challenge of allergenicity of apple cultivars. Journal of Allergy and Clinical Immunology, 116, 1080-1086.

Borejsza-Wysocka, E. E., Malnoy, M., Aldwinckle, H. S., Geider, K., Kim, W. S., \& Beer, S. V. (2008). Increased resistance to fire blight by expression of the phi-Ea1h phage depolymerase gene with constitutive and inducible promoters, translation enhancer and signal sequence in transgenic apple. Acta Horticulture, 793, 293-296.

Brenna, O., Pompei, C., Ortolani, C., Pravettoni, V., Farioli, L., \& Pastorello, E. A. (2000). Technological processes to decrease the allergenicity of peach juice and nectar. Journal of Agricultural and Food Chemistry, 48, 493-497.

Carnés, J., Ferrer, A., \& Fernández-Caldas, E. (2006). Allergenicity of 10 different apple varieties. Annals of Allergy, Asthma and Immunology, 96, 564-570.

Cheng, F. S., Weeden, N. F., Brown, S. K., Aldwinckle, H. S., Gardiner, S. E., \& Bus, V. G. (1998). Development of a DNA marker for $V m$, a gene conferring resistance to apple scab. Genome, 41, 208-214.

Cook, C., Heath, F., \& Thompson, R. L. (2000). A meta-analysis of response rates in web- or internet-based surveys. Educational and Psychological Measurement, 60, 821-836.

Cornelisse-Vermaat, J. R., Voordouw, J., Yiakoumaki, V., Theodoridis, G., \& Frewer, L. J. (2008). Food-allergic consumers' labelling preferences: A cross-cultural comparison. European Journal of Public Health, 18, 115-120.

Cox, D. N., Evans, G., \& Lease, H. J. (2008). Australian consumers' preferences for conventional and novel sources of long chain omega-3 fatty acids: A conjoint study. Food Quality and Preference, 19(3), 306-314.

Durel, C. E., Parisi, L., Laurens, F., Van de Weg, W. E., Liebhard, R., Koller, B., et al. (2003). Genetic dissection of partial resistance against two monoconidial strains of the new race 6 of Venturia inaequalis in apple. Genome, 46, 224-234.

Deliza, R., Rosenthal, A., Hedderley, D., MacFie, H. J. H., \& Frewer, L. J. (1999). The importance of brand, product information and manufacturing process in the development of novel environmentally friendly vegetable oils. Journal of International Food and Agribusiness Marketing, 10, 67-77.

Dodo, H. W., Konan, K. N., Chen, F. C., Egnin, M., \& Viquez, O. M. (2008). Alleviating peanut allergy using genetic engineering: The silencing of the immunodominant allergen Ara h 2 leads to its significant reduction and a decrease in peanut allergenicity. Plant Biotechnology Journal, 6, 135-145.

Faize, M., Sourice, S., Dupuis, F., Parisi, L., Gautier, M. F., \& Chevreau, E. (2004). Expression of wheat puroindoline-b reduces scab susceptibility in transgenic apple (Malus $\times$ domestica Borkh). Plant Science, 167, 347-354.

Fernandez-Rivas, M., \& Miles, S. (2004). Food allergies: Clinical and psychosocial perspectives. In E. N. C. Mills \& P. R. Shewry (Eds.), Plant food allergies (pp. 1-23). Oxford: Blackwell Science Ltd.

Frewer, L., Howard, C., \& Shepherd, R. (1997). Public concerns in the United Kingdom and specific applications of genetic engineering: Risk, benefit, and ethics. Science, Technology and Human Values, 22, 98-124.
Frewer, L. J., Howard, C., Hedderley, D., \& Shepherd, R. (1997). Consumer attitudes towards different food-processing technologies used in cheese production - The influence of consumer benefit. Food Quality and Preference, 8, 271-280.

Frewer, L. J., Lassen, B., Kettlitz, J., Scholderer, J., Beekman, K., \& Berdal, G. (2004). Societal aspects of gentically modified foods. Food and Chemical Toxicology, 72, 1181-1193.

Fritsch, R., Bohle, B., Vollmann, U., Wiedermann, U., Jahn-Schmid, B., Krebitz, M. et al. (1998). Bet v 1, the major birch pollen allergen, and Mal d 1, the major apple allergen, cross-react at the level of allergen-specific $T$ helper cells. Journal of Allergy and Clinical Immunology, 102, 679-686.

Gaskell, G., Allansdottir, A., Allum, N., Corchero, C., Fischler, C., Hampel, J. (2006). Eurobarometer 64.3: Europeans and Biotechnology in 2005: Patterns and Trends. INRA.

Gilissen, L. J. W. J., Bolhaar, S. T. H., Matos, C. I., Rouwendal, G. J. A., Boone, M. J., Krens, F. A., et al. (2005). Silencing the major apple allergen Mal d 1 by using the RNA interference approach. Journal of Allergy and Clinical Immunology, 115, 364-369.

Gowland, M. H. (2001). Food allergen avoidance - The consumer's viewpoint. Allergy, 56, 117-120.

Hair, J. F. J., Black, W. C., Babin, B. J., Andserson, R. E. (in press). Chapter 6 Conjoint Analysis. In: Multivariate Data Analysis: A global Perspective (7th ed.).

Herman, E. M., Helm, R. M., Jung, R., \& Kinney, A. J. (2003). Genetic modification removes an immunodominant allergen from soybean. Plant Physiology, 132, 36-43.

Hourihane, J. O. (2001). The threshold concept in food safety and its applicability to food allergy. Allergy: European Journal of Allergy and Clinical Immunology, Supplement, 56, 86-90.

Jacobsen, E., \& Schouten, H. J. (2007). Cisgenesis strongly improves introgression breeding and induced translocation breeding of plants. Trends in Biotechnology, 25, 219-223.

Jan, M. S., Fu, T. T., \& Huang, C. L. (2007). A conjoint/logit analysis of consumers responses to genetically modified Tofu in Taiwan. Journal of Agricultura Economics, 58, 330-347.

Kootstra, H. S., Vlieg-Boerstra, B. J., \& Dubois, A. E. J. (2007). Assessment of the reduced allergenic properties of the Santana apple. Annals of Allergy, Asthma and Immunology, 99, 522-525.

Lake, A. A., Hyland, R. M., Mathers, J. C., Rugg-Gunn, A. J., Wood, C. E., \& Adamson, A. J. (2006). Food shopping and preparation among the 30-somethings: Whose job is it? (The ASH30 study). British Food Journal, 108, 475-486.

Le, L. Q., Mahler, V., Lorenz, Y., Scheurer, S., Biemelt, S., Vieths, S., et al. (2006) Reduced allergenicity of tomato fruits harvested from Lyc e 1-silenced transgenic tomato plants. Journal of Allergy and Clinical Immunology, 118 1176-1183.

Lüttkopf, D., Müller, U., Skov, P. S., Ballmer-Weber, B. K., Wüthrich, B., Hansen, K. S. et al. (2002). Comparison of four variants of a major allergen in hazelnut (Corylus avellana) Cor a 1.04 with the major hazel pollen allergen Cor a 1.01 Molecular Immunology, 38, 515-525.

Maas, C. J. M., \& Snijders, T. A. B. (2003). The multilevel approach to repeated measures for complete and incomplete data. Quality and Quantity, 37, 71-89.

McCabe, M., Lyons, R. A., Hodgson, P., Griffiths, G., \& Jones, R. (2001). Management of peanut allergy. Lancet, 357(9267), 1531-1532.

Miles, S., Bolhaar, S., Gonzáez-Mancebo, E., Hafner, C., Hoffmann-Sommergruber, K. Fernández-Rias, M., et al. (2005). Attitudes towards low-allergen food in food allergic consumers. Nutrition and Food Science, 35, 220-228.

Miles, S., \& Frewer, L. J. (2001). Investigating specific concerns about different food hazards. Food Quality and Preference, 12, 47-61.

Mills, E. N. C., Valovirta, E., Madsen, C., Taylor, S. L., Vieths, S., Anklam, E., et al. (2004). Information provision for allergic consumers - Where are we going with food allergen labelling? Allergy, 59, 1262-1268.

Ortolani, C., Bruijnzeel-Koomen, C., Bengtsson, U., Bindslev-Jensen, C., Björkstén, B. Høst, A., et al. (1999). Controversial aspects of adverse reactions to food. Allergy: European Journal of Allergy and Clinical Immunology, 54, 27-45.

Primavesi, L., Brenna, O. V., Pompei, C., Pravettoni, V., Farioli, L., \& Pastorello, E. A. (2006). Influence of cultivar and processing on cherry (Prunus avium) allergenicity. Journal of Agricultural and Food Chemistry, 54, 9930-9935.

Rona, R. J., Keil, T., Summers, C., Gislason, D., Zuidmeer, L., Sodergren, E., et al. (2007). The prevalence of food allergy: A meta-analysis. Journal of Allergy and Clinical Immunology, 120, 638-646.

Schenk, M. F., Fischer, A. R. H., Frewer, L. J., Gilissen, L. J. W. J., Jacobsen, E., \& Smulders, M. J. M. (2008). The influence of perceived benefits on acceptance of GM applications for allergy prevention. Health, Risk and Society, 10, 263-282.

Siegrist, M. (1998). Belief in gene technology: The influence of environmental attitudes and gender. Personality and Individual Differences, 24, 861-866.

Titchener, G. D., \& Sapp, S. G. (2002). A comparison of two approaches to understanding consumer opinions of biotechnology. Social Behavior and Personality, 30, 373-381.

van Kleef, E., van Trijp, H. C. M., \& Luning, P. (2005). Consumer research in the early stages of new product development: A critical review of methods and techniques. Food Quality and Preference, 16, 181-201.

van Putten, M. C., Frewer, L. J., Gilissen, L. J. W. J., Gremmen, B., Peijnenburg, A. A. C. M., \& Wichers, H. J. (2006). Novel foods and food allergies: A review of the issues. Trends in Food Science and Technology, 17, 289-299.

Wangorsch, A., Ballmer-Weber, B. K., Rösch, P., Holzhauser, T., \& Vieths, S. (2007) Mutational epitope analysis and cross-reactivity of two isoforms of Api $g$ 1, the major celery allergen. Molecular Immunology, 44, 2518-2527. 
Wiche, R., Gubesch, M., Konig, H., Fotisch, K., Hoffmann, A., Wangorsch, A., et al (2005). Molecular basis of pollen-related food allergy: identification of a second cross-reactive IgE epitope on Pru av 1, the major cherry (Prunes avium) allergen. Biochemical Journal, 385, 319-327.

Yee, W. M. S., Traill, W. B., Lusk, J. L., Jaeger, S. R., House, L. O., Moore, M., et al. (2008). Determinants of consumers' willingness to accept GM foods. International Journal of Biotechnology, 10, 240-259.
Zechendorf, B. (1994). What the public thinks about biotechnology - Better than synthetic food but worse than organ-transplantation - A survey of opinion polls. Biotechnology, 12, 870-875.

Zeiger, R. S. (2003). Food allergen avoidance in the prevention of food allergy in infants and children. Pediatrics, 111, 1662-1671. 